$A R T I C U L O \quad D E$

IN $V E S T$ I G A C I Ó $N$

CIIEN N TIIFIICA

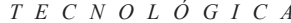

\section{EL LABERINTO DE LAS RADIOS COMUNITARIAS EN BOLÍVAR: ENTRE LA SUBSISTENCIA Y EL APORTE SOCIAL AL DESARROLLO COMUNITARIO}

\author{
THE MAZE OF COMMUNITY RADIO IN BOLIVAR \\ BETWEEN SUBSISTENCE AND SOCIAL CONTRIBUTION \\ TO COMMUNITY DEVELOPMENT
}

\author{
Por: Bertha Lucía Arnedo Redondo* \\ Dais Hernández Guzmán** \\ Jenny Juliet Jurado Vargas ${ }^{* * *}$
}

Recibido 30 Julio 2013. Aprobado 17 de febrero 2014.

\title{
RESUMEN
}

Este articulo muestra los resultados de la investigación "El papel de la radio comunitaria en el departamento de Bolívar. Análisis de su incidencia en el desarrollo del departamento", el cual se desarrolló en las seis ZODES de Bolívar y surgió de la necesidad de conocer la realidad de la radio comunitaria en dicho departamento, entendiendo que la radio comunitaria cumple un papel significativo en los lugares donde actúa, convirtiéndose en instrumento de educación y cultura en el desarrollo popular. Con base en los hallazgos se confrontan las situaciones encontradas con el deber ser de las emisoras comunitarias según el Ministerio de Tecnologías de la Información y las Comunicaciones. Finalmente, después de la discusión, se presentan reflexiones en torno al papel de la radio comunitaria en Bolívar, como un aporte desde la Universidad para que Estado, sociedad y universidad arropen estas estrategias comunicativas y las fortalezcan.

Palabras claves: Radio, participación, desarrollo, comunidad, comunicación.

\section{ABSTRACT}

This article shows the results of the research "The role of community radio in the department of Bolivar. Analysis of its impact on the development of the department. "Which was developed in the six ZODES Bolivar and arose from the need to know the reality of community radio in that department, understanding that community radio plays a significant role in the places where it operates, become the means of education and culture in popular development. Based on the findings are confronted with situations encountered must be community radio stations according to the ministry of communication. Finally, after discussion, there are reflections on the role of community radio in Bolivar.

Key words: Radio, participation, development, community, communication. 


\section{Introducción}

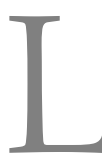

as radios comunitarias entendidas como un \rfloor$_{\text {servicio público radial }}$ de carácter participativo y pluralista, deben cumplir un papel significativo y de peso en las comunidades en las que se encuentran y por tanto trascender de lo instrumental y operativo, para instalarse como verdaderas estrategias comunicativas en pro de la interacción social. Sin embargo, esto no ocurre por inercia, sino que depende de las características propias de cada comunidad y el manejo que se le esté dando a cada emisora. De eso se trató la investigación "EL PAPEL DE LA RADIO COMUNITARIA EN BOLÍVAR: ANÁLISIS DE SU INCIDENCIA EN EL DESARROLLO SOCIAL DEL DEPARTAMENTO", un proyecto avalado y financiado por la Vicerrectoría de Investigaciones de la Universidad de Cartagena, dentro de su política de fortalecimiento a la investigación, desarrollado en el año 2012, por el semillero de investigación, vinculado al grupo 'Comunicación, Educación y Cultura' del programa de Comunicación Social.

Con él se indagó sobre el estado de las emisoras comunitarias en el departamento de Bolívar, y se realizó un diagnóstico sobre el papel de la radio comunitaria, en las dinámicas de desarrollo y participación, y el cumplimiento que estas le dan a la normatividad radial colombiana que las regula. Ello, conllevó a identificar también la corresponsabilidad entre el Estado, las organizaciones concesionarias y las comunidades, en aras de posibilitar que tanto los intereses, como las necesidades y proyecciones de cada comunidad, confluyan en pro del avance de cada región. Teniendo en cuenta lo anterior, la revisión literaria que da solidez teórica a la investigación, estuvo direccionada a los conceptos de desarrollo y participación, utilizando como plataforma la normatividad colombiana en cuanto a la radiodifusión y el carácter histórico y esencial de la radio como medio de comunicación popular. 
${ }^{1}$ Arnedo, Berta, mencionando a Latouche en su obra Sobrevivir al desaOnda de la Radio", 2009.

${ }^{2} \mathrm{ONU}$. Informe de Desarrollo Humano de 1990
Hablar de emisoras comunitarias, es hablar de comunicación y desarrollo, y para entender el concepto de desarrollo y cómo este se asocia a la radio, se hizo necesario comprender la profunda transformación que ha tenido el concepto de desarrollo y cómo el mismo se articula a la comunicación, y en este caso particular, al funcionamiento de un medio de comunicación como la radio.

\section{¿Cómo hemos entendido el desarrollo?}

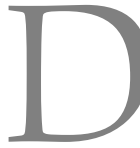
esde su aparición a mediados del siglo XX, el concepto de desarrollo ha sido abordado por los expertos desde diversos enfoques: económico, político, social, ambiental, de desarrollo humano y, el más reciente el de seguridad humana. Durante sesenta años, este concepto ha estado evolucionando, mutando, transformándose, reconstruyéndose, reinventándose. En ese lapso, el desarrollo se ha movido en iguales condiciones con los cambios experimentados por la sociedad mundial.

Durante la primera década de la posguerra el desarrollo estuvo ligado al crecimiento económico; la historia registra el surgimiento de los primeros estudios del desarrollo en el año 1949, cuando el Presidente de los Estados Unidos, Harry Truman, en un discurso ante el Congreso de su país, calificó a un gran porcentaje de las naciones del mundo como regiones subdesarrolladas. De esta forma, nacía el concepto que enmarca una cuasi infinita diversidad de modos de vida en el hemisferio sur en una única condición: subdesarrollada, lo que a su vez se constituyó en una provocación y meta a alcanzar, por parte de cada pueblo ubicado en la misma: el desarrollo ${ }^{1}$.

Desde entonces y en su trayectoria, estudio y aplicación, el término desarrollo mostró la necesidad de trascender los indicadores tradicionales enfocados en lo económico, para iniciar nuevas formas y mecanismos que integraran componentes como la esperanza de vida, los niveles de escolaridad, las libertades y las oportunidades para todos los grupos sociales. Esta nueva apuesta filosófica, social, política y por supuesto económica, trabajó en la creación de un ambiente adecuado en el que los seres humanos pudieran gozar de una vida en condiciones más favorables y equilibradas ${ }^{2}$. Nació la era del bienestar, la exigencia de atender a corto o largo plazo, los objetivos sociales del crecimiento; es decir, lo que para muchos era solo desarrollismo se convirtió en desarrollo, y en este escenario, las ciencias sociales y humanas hicieron sus apuestas y los medios de comunicación masivos concretaron su participación con propuestas incluyentes y formativas que resaltaron el papel y la función social que podían cumplir en pro de la búsqueda de la anhelada categoría "país desarrollado". 
En este escenario, la comunicación ha sido un elemento esencial en la planificación del cambio social, y dentro de ese proceso el uso de los medios y particularmente el de la radio, por sus ya reconocidas bondades y características. Todas las ventajas de la radio como medio de comunicación se materializan en la aplicación del medio al servicio comunitario, particularmente por las características de la audiencia con quien se va a trabajar.

En primer lugar, la naturaleza radiofónica permite su utilización, acceso y contacto fácilmente; y en ese sentido, los campesinos, estudiantes, docentes, amas de casa, pueden escucharla mientras realizan sus tareas cotidianas, sin que ello les afecte. De otra parte, por sus bajos costos, la radio es el medio al que más pueden acceder las poblaciones de escasos recursos, e incluso, haciéndose cargo, ellos mismos, de los costos de una estación de radio y de la producción de programas para la radio ${ }^{3}$. Adicionalmente, bajo la figura de las veedurías ciudadanas, la misma comunidad forma parte del proyecto comunicativo no solo como oyente, sino como vigilante del cumplimiento de las funciones para las que fue creado. De esta forma, la comunidad se compromete y de manera conjunta deciden sobre sus intereses y necesidades.

Sumado a las funciones que históricamente se le han atribuido a la radio de informar, educar y entretener; en el desarrollo, la radio ha sido multifacética ya que ha contribuido a la transmisión de mensajes, al mejoramiento del trabajo y la consolidación de organizaciones comunitarias, a ampliar el foro para el diálogo social, a proporcionar la construcción de capacidades de la comunidad y al incremento de la conciencia y el conocimiento sobre los temas de la comunidad. Experiencias como Radio Sutatenza (Colombia), las radios mineras (Bolivia), las radios populares (Cuba), entre muchas otras en el mundo, evidencian que la radio comunitaria ha sido el medio más eficaz para ampliar la voz de la gente en asuntos de interés colectivo.

Partiendo de lo anterior, se entiende porque el término radio comunitaria hoy se ha constituido en el genérico dentro de todas las demás categorías de radio para el cambio social. De alguna manera, de ella se desprendieron las demás ofertas y apuestas radiales enmarcadas en el desarrollo. Esta radio, ha tenido como objeto fundamental satisfacer los intereses y necesidades de comunicación de las comunidades, regiones o zonas geográficas concretas ${ }^{4}$. Lo que se articula de manera muy clara con lo que un autor como S. Boisier (2004), afirma del desarrollo y sus fines cuando señala que este adquiere sentido solo cuando "se trata de generar transformaciones sociales, hecho con capital humano y gestado desde la misma comunidad, es decir a través de la participación".

${ }^{3}$ Arnedo, Berta. "Radio y cambio social "Capítulo $\checkmark$ En la Onda de la Radio Universidad de Cartagena, 2009

${ }^{4}$ Najarro, L: Las potencianitaria Cuba 2007.

Palobra No. 14. Agosto de 2014 
Esto, se confronta con el surgimiento formal en la década de los ochenta de la radio comunitaria en Colombia en cuyo marco, conceptos como la participación y lo colectivo, asumieron un papel protagónico pues según el Ministerio de Tecnologías de la Información y la Comunicación, es la participación comunitaria la que garantiza en gran medida la sostenibilidad de estos proyecto sonoros.

Fue esencial acudir a los planteamientos del radialista latinoamericano, José Ignacio López Vigil, quien al referirse a la radio comunitaria señala que su programación tiene dos sentidos, igual que un puente. Esto es, que puede y debe recorrerse de allá para acá- desde las expectativas y necesidades del público_y de acá para allá _desde las ofertas y posibilidades de la radio. En ese orden de ideas, la programación no debe ser exclusivamente musical pues la sola música no basta para transformar las realidades, por más buena que sea. Es importante que la radio se haga en la plaza y en la calle; esto es, que de espacio al debate, al dramatizado, a la intermediación, la actualidad y la formación. Un medio comunitario que no sea altamente participativo no es en realidad lo que dice ser.

Ahora bien, la normatividad sonora en Colombia y la clasificación de este medio en el país contempla que la radio, en sus diferentes tipologías: Comercial, De interés público y Comunitaria, es un medio de comunicación que sigue vigente en nuestro contexto y tal vez sin pretenderlo, adquirió un compromiso cuasi mundial con las emisoras de corte comunitario, al poseer uno de los ejemplos más productivos y eficaces en materia de formación, trabajo colectivo y transformación social: Radio Sutatenza, el proyecto que por más de 50 años, entre 1948 y 1990, benefició a cerca de ocho millones de analfabetas, manejando sus cinco ejes esenciales (salud, alfabeto, números, trabajo espiritualidad) . Con este importante referente, es consecuente pensar que las radios comunitarias existentes y las que están por surgir, tienen una buena práctica de la cual tomar elementos que les orienten en su ejercicio mediático.

\section{El papel de la comunicación participativa}

ara el Ministerio de Nuevas Tecnologías, Información y Comunicación, en el marco de su curso virtual Radio y compromiso social, en convenio con la Universidad de Antioquia, a través de la Red Periodismo de Hoy, ha sido enfático en mencionar que en el panorama del servicio de radio comunitaria en Colombia, la comunicación participativa ha de ser el motor que dinamice a la comunidad, en el entendido que la comunicación en su más 
amplia y profunda definición se enfoca en las formas como los seres humanos viven, se relacionan entre sí y enriquecen sus imaginarios y representaciones colectivas, lo que conlleva a la construcción de tejido social y por tanto a la transformación de las comunidades. En este sentido, la comunidad deja de ser el objeto de la comunicación y pasa a ser sujeto indispensable en el diálogo permanente. Por ello, la comunicación participativa se desenvuelve en los medios comunitarios haciendo un aporte distintivo y único en la relación emisor receptor, los cuales según el MINTIC trascienden de la siguiente manera:

-Las comunidades dejan de ser receptores pasivos de información y pasan a tomar decisiones sobre sus vidas.

-Las comunidades trabajan por procesos desde el interior de las mismas, en lugar de responder a las campañas externas que les llegan de otros actores.

-Las comunidades entienden que desde la comunicación los procesos trascienden el mero entretenimiento pasajero, porque es necesario tomarse el tiempo para apropiarse de aquello que redunde en beneficios concretos.

-Con la comunicación participativa no existen los individuos aislados, sino los colectivos comprometidos.

-No hay modelos, campañas ni programas estándar. Cada propuesta es específica y responde a las necesidades y/o características de cada comunidad.

-En lugar de mecanismos de persuasión para que los comportamientos se amolden a una idea de manera inmediatista, la comunicación participativa, propende por la concientización y comprensión profunda de la realidad social.

Desde este marco teórico y normativo que fundamentó la investigación, se visualiza el laberinto de las radios comunitarias de Bolívar, toda vez que las mismas funcionan en el centro de muchos caminos, los cuales no siempre las conducen al cumplimiento de sus funciones y éxito del proyecto por situaciones como: la realidad social misma de la región, las condiciones de la emisora, la apatía, desconocimiento y pasividad de las audiencias, la distancia con el Ministerio, el casi nulo trabajo en red. 


\section{Metodología}

T a investigación estuvo orientada desde un enfoque cualitativo y una tipología descriptiva. La muestra fue escogida teniendo en cuenta lque Bolívar, debido a su extensión, geografía y gran diversidad, se encuentra actualmente dividida en seis Zonas de Desarrollo Económico y Social (ZODES): Zodes Dique, Zodes Montes de María, Zodes Mojana bolivarense, Zodes Depresión momposina, Zodes Loba bolivarense y Zodes Magdalena medio; por lo tanto, se consideró pertinente en aras de estudiar lo más amplio y equlibradamente posible el departamento, escoger un municipio de cada Zodes, en representación del mismo, asumiendo que al hacer parte de un mismo grupo de municipios, sus características y posibles hallazgos no serían similares al resto (los municipios de un mismo Zodes, comparten prácticas culturales, productivas, entre otras, similares). El siguiente paso fue ubicar en cada Zodes un municipio que contara con una emisora comunitaria, en vigencia y legalmente constituida ante el Ministerio de la Información y de las Comunicaciones, para lo cual, después de que el Ministerio notificara formalmente las emisoras comunitarias con licencias vigentes en Bolívar en la actualidad, la muestra final, quedó de la siguiente manera:

MUNICIPIOS ESCOGIDOS POR ZODES DEL DPTO. DE BOLÍVAR

\begin{tabular}{|c|c|c|}
\hline ZODES & MUNICIPIO & EMISORA \\
\hline Dique & Arjona & Arjona Estéreo \\
\hline Montes de María & Carmen de Bolívar & Carmen Estétereo \\
\hline Mojana Bolivarense & Magangué & Cheverisima Estéreo \\
\hline Depresión Momposina & Mompox & Galaxia Estéreo \\
\hline Loba Bolivarense & San Martín de Loba & Lobana Estéreo \\
\hline Magdalena Medio & Simití* & La Original Estéreo* $^{*}$ \\
\hline
\end{tabular}

Fuente: resultados de la investigación "El papel de la radio comunitaria en Bolívar. Análisis de su incidencia en el desarrollo del departamento".

*Varios intentos fueron hechos para acordar la visita a la emisora de municipio de Simití, pero no fue posible. Las razones dadas por el director de la emisora estuvieron asociadas a temas de seguridad.

Los instrumentos escogidos para hacer la recolección de la información fueron: a. La observación, realizada esencialmente a las instalaciones de la emisora, a sus dinámicas internas y externas; b. Indagación documental, hecha alrededor de la radio comunitaria, la normatividad colombiana sobre radiodifusión, el plan de desarrollo del departamento de Bolívar y las características sociales, geográficos y económicas de los municipios bolivarenses. c. La entrevista, llevada a cabo con los directores y demás miembros de las emisoras; y finalmente, el sondeo a la comunidad, con la intención de conocer su percepción frente a la emisora de sus municipios. Adicionalmente, el equipo 
de investigadores, decidió como valor agregado a la metodología aplicada, el análisis de contenido buscando constatar la información recopilada con la aplicación de los demás instrumentos e indagar en los contenidos emitidos por las emisoras.

Durante la visita hecha a los distintos municipios, se identificaron dos aspectos constantes y comunes entre emisoras y comunidades: desconfianza hacia las reales intenciones de los investigadores, relacionadas con las secuelas dejadas por el conflicto armado que vivió el departamento hasta hace poco tiempo; y de otra parte, la menguada disposición para mostrar y hablar sobre el trabajo que se hace en cada una de sus radios comunitarias, justificada en la percepción que tienen sobre la labor del Ministerio de Tecnologías de la Información y las Comunicaciones, la cual encuentran más fiscalizadora que acompañante, por lo que el temor se enfocaba en que de la información suministrada resultaran procesos sancionatorios o requerimientos de tipo administrativo/financiero.

\section{Resultados}

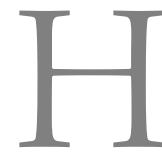

abiendo profundizado en lo que implica la participación y teniendo en cuenta el enfoque que el MINTIC le da con respecto a este tipo de emisoras y por tanto a los procesos de cambio social, se logró identificar una concepción bastante ligera del significado de la misma, la cual asumen y limitan a la forma común como los oyentes en cada municipio se relacionan con la emisora, a través de las llamadas telefónicas, envío de mensajes y correos, generalmente usados para enviar saludos, felicitaciones, solicitar canciones u opinar. Otra forma, destacada es el fácil acceso físico que tiene la comunidad a la emisora, a donde se dirigen en ocasiones a solicitar servicios sociales, pautas publicitarias y hacer preguntas de todo tipo. Aún así, ello suele suceder esporádicamente. Los directores de las emisoras, coincidieron en manifestar que entienden cualquier contacto del público con ellos, como un acto de participación, refiriéndose a situaciones en dónde se celebran días especiales (del padre, la madre, amor y amistad, etc.), con entrega de regalos, visitas a los barrios en fechas conmemorativas y cuando se realizan sondeos en las calles a las personas. "el pueblo de Arjona hace parte de la emisora, ejemplo, lo que vamos a hacer el lunes festivo y vamos a celebrar el día del padre, aquí viene por lo menos el 10\% de la población, con los regalos que vamos a hacer, con el tipo de programa que vamos a hacer" manifestó Oswaldo Jimenez director de Arjona Estereo. 
Lo anterior, concuerda con el hecho de que el 70\% de la comunidad de los municipios estudiados, manifestó en los sondeos el desconocimiento de todas las posibilidades que cobija la categoría comunitaria, la confunden con una emisora comercial y enfocan su función de manera única al entretenimiento. Muestra de ello es que a la pregunta ¿Para qué sirve una emisora comunitaria? Se escuchan respuestas como "Francamente no sé" manifestada por un habitante del Carmen de Bolívar o " No" como señaló un habitante de Monpox. Esto, se da a su vez porque las parrillas de programación revisadas y actualmente al aire están constituidas en un 75\% por el formato musical. En ese sentido, la participación también se ve menguada. Las propuestas de otros formatos hablados son hechas desde la emisora y son pocas las ocasiones en las que los oyentes o personas externas se interesan en proponer nuevos programas o temáticas. Sin embargo, ese $25 \%$ de las emisoras cuenta con la figura de Veeduría ciudadana, a través de la cual han ido dándose avances significativos, aunque aún no resultan suficientes. Los siguientes son algunos apartes extraídos de las entrevistas hechas a los radialistas comunitarios, con respecto a cómo entienden el desarrollo y los aportes que desde la emisora están haciendo a la región.

\section{Desarrollo}

\begin{tabular}{|c|c|c|}
\hline Emisora & Concepto de desarrollo & Contribución a la región \\
\hline $\begin{array}{l}\text { Director } \\
\text { Lobana Est. }\end{array}$ & $\begin{array}{l}\text { "Tentiendo desarrollo desde } \\
\text { mi punto de vista como una } \\
\text { forma de avance". }\end{array}$ & $\begin{array}{l}\text { "Antes de Lobana y después de Lobana"... } \\
\text { La contribución al desarrollo que esta } \\
\text { emisora considera estar aportando tiene } \\
\text { que ver con el cambio de imaginario que } \\
\text { se tenía sobre el pueblo y sus habitantes, } \\
\text { pues eran prejuzgados como presuntos } \\
\text { guerrilleros. Con la emisora, esa imagen } \\
\text { se ha ido desdibujando mostrando la real } \\
\text { identidad de este municipio: "... a crear } \\
\text { nuestra identidad como tal, a que la gente } \\
\text { a través de la radio se culturice, por así } \\
\text { decirlo, se despierte, tenga otra visión tanto } \\
\text { política, como social, cultural" }\end{array}$ \\
\hline $\begin{array}{l}\text { Director de } \\
\text { Galaxia Est. }\end{array}$ & $\begin{array}{l}\text { "El desarrollo, es progreso, } \\
\text { salir adelante con el cambio". }\end{array}$ & $\begin{array}{l}\text { Con el programa de las veedurías } \\
\text { ciudadana, promovidos desde la } \\
\text { emisora, han percibido que en ese } \\
\text { espacio la gente está pensando de otra } \\
\text { forma y se han ido educando en muy } \\
\text { corto tiempo, al decirles frecuentemente: } \\
\text { "usted tiene estas herramientas, tiene el } \\
\text { derecho de petición, tiene la tutela, usted } \\
\text { como ciudadano tiene el derecho de pedir } \\
\text { información y hacer de veedor". }\end{array}$ \\
\hline
\end{tabular}




\begin{tabular}{|c|c|c|}
\hline $\begin{array}{c}\text { Director } \\
\text { Arjona Est. }\end{array}$ & $\begin{array}{l}\text { "Desarrollo es la evolución } \\
\text { total de la gente hacia un } \\
\text { modo de vida más sano". }\end{array}$ & $\begin{array}{l}\text { Consideran inicialmente haber } \\
\text { promovido el desarrollo económico } \\
\text { del municipio, al haber incentivado la } \\
\text { llegada de empresas de cadena y demás } \\
\text { negocios al municipio, a través de la } \\
\text { promoción de Arjona desde la emisora. } \\
\text { Además han generado cambios en los } \\
\text { hábitos y costumbres que perjudicaban } \\
\text { al municipio, un ejemplo citado fue el } \\
\text { manejo de la recolección de basuras: } \\
\text { "aquí se le entregaba la basura al } \\
\text { carretillero y el la botaba en cualquier } \\
\text { basurero satélite, entonces imagínate ese } \\
\text { trabajo de concientizar a la gente en la } \\
\text { recolección de la basura y el manejo de los } \\
\text { residuos sólidos" }\end{array}$ \\
\hline $\begin{array}{l}\text { Director } \\
\text { Cheverísima } \\
\text { Est. }\end{array}$ & $\begin{array}{l}\text { "Desarrollo es la articulación } \\
\text { entre todos para beneficiarnos } \\
\text { en algo para vivir mejor". }\end{array}$ & $\begin{array}{l}\text { Se destaca haber generado confianza en } \\
\text { el pueblo, de tal manera que las personas } \\
\text { parecen sentirse satisfecha con la manera } \\
\text { en que se difunde la cultura de Magangué. } \\
\text { Promueven acciones sociales en las que } \\
\text { ayudan a personas con problemas de } \\
\text { salud: "Por ejemplo el último que hicimos } \\
\text { fue que había una familia con un problema } \\
\text { de salud de cuestiones congénitas e hicimos } \\
\text { una campaña la comunidad, nosotros y con- } \\
\text { seguimos una silla de ruedas, conseguimos } \\
\text { unos recursos para que las personas que es- } \\
\text { taban mal se quedaran aquí y el que tenía } \\
\text { posibilidades lo mandamos a un centro asis- } \\
\text { tencial de mayor grado de los que están acá; } \\
\text { por ejemplo, lo mandamos para Medellín." }\end{array}$ \\
\hline $\begin{array}{c}\text { Director } \\
\text { Carmen Est. }\end{array}$ & $\begin{array}{l}\text { “...el desarrollo es un bien- } \\
\text { estar colectivo en condicio- } \\
\text { nes de equidad y de igual- } \\
\text { dad, en donde los derechos } \\
\text { y garantías fundamentales } \\
\text { se ejerciten libremente, sin } \\
\text { condicionamientos ni dificul- } \\
\text { tad alguna” }\end{array}$ & $\begin{array}{l}\text { La contribución al desarrollo social del } \\
\text { municipio se da en el empoderamiento } \\
\text { que le han dado a las personas para ex- } \\
\text { presarse a través del medio, consolidan- } \\
\text { do la democracia, sobre todo en la resti- } \\
\text { tución de derechos de las víctimas y de } \\
\text { la población en sí, después del conflicto } \\
\text { armado: "le enseñamos a la gente que hay } \\
\text { un medio y que podían expresarse a través } \\
\text { de él, que tenías que superar ese miedo, que } \\
\text { aún persiste. Aquí nadie se atrevía a opi- } \\
\text { nar, nadie se atrevía a decir nada". }\end{array}$ \\
\hline
\end{tabular}

Fuente: Entrevistas a directores de emisoras comunitarias.

De otra parte, para conocer y valorar si el contenido de la programación radial de estas emisoras responde a las exigencias asignadas por la ley, es necesario tener en cuenta la Resolución 0415 de 2010, la cual reglamenta a estas emisoras, dispone de la programación que: "está orientada a generar 
5Resolución número 00415 de 13 abr. 2010 sonora comunitaria pitulo 2 Clasifica, cadel Servicio de Radiodifusión Sonora artículo 18 Orientación de la programación inciso $-\mathrm{c}$ espacios de expresión, información, educación, comunicación, promoción cultural, formación, debate y concertación que conduzcan al encuentro entre las diferentes identidades sociales y expresiones culturales de la comunidad, dentro de un ámbito de integración y solidaridad ciudadana y, en especial, a la promoción de la democracia, la participación y los derechos fundamentales de los colombianos que aseguren una convivencia pacífica"

Teniendo en cuenta lo plasmado anteriormente se encontró que dos de las emisoras comunitarias cumplen medianamente la norma en cuanto a programación, pues solo emiten musicales e identificadores como emisora comunitaria, pero no existen otros formatos ni contenidos en lo que se haga visible la promoción de la democracia y la participación.

Una sola de las emisoras estudiadas, da cumplimiento en su totalidad a la norma, promoviendo los derechos fundamentales e incentivando a las personas a tener una convivencia pacífica.

De otra parte, en dos de los cinco municipios visitados, sus emisoras construyen la parrilla de programación de acuerdo con las llamadas del público, mientras que las demás, realizan este trabajo a través de sus juntas de programación, y en ese orden de ideas, solo una emisora tiene en cuenta las necesidades o expectativas de la población, para diseñar su propuesta radiofónica. En todas las emisoras comunitarias seleccionadas para la investigación, la programación es de tipo generalista, lo que significa que es pensada en una audiencia amplia, sin que se tengan en cuenta los grupos específicos (niños, mujeres, afrodecendientes, indígenas, tercera edad, jóvenes, campesinos, etc), lo que a su vez evidencia que las emisoras de este tipo nunca han realizado estudios de audiencias, factor que dificulta la sostenibilidad social de los proyectos, al no conocer quiénes son y qué necesitan realmente los grupos que conforman sus audiencias.

En cuanto a los tipos de formatos que trascienden el musical, se encontró que todas las emisoras transmiten información noticiosa sobre el municipio y la región, sin que ello corresponda necesariamente a un programa noticioso en el estricto sentido; pues según el artículo 36 de la Resolución 415 de 2010 para emitir este tipo de programa es necesaria una licencia especial; sin embargo, estos momentos de la parrilla son para los oyentes de vital importancia e incluso, los de mayor interés. Actualmente, solo dos de las emisoras indagadas tienen este permiso, el 
resto carece de él y no lo consideran necesario por no tener programas formales informativos, afirman sus directores.

A pesar de todo lo anterior, las radios comunitarias cumplen con la exigencia de colaborar con el Ministerio TIC y demás Ministerios, cada vez que necesiten emitir propagandas o informaciones de interés general, de manera gratuita.

Ahora bien se hallaron tres factores del contexto de las emisoras que influyen en el ejercicio de la radio comunitaria en el departamento de Bolívar:

En primer lugar la falta de apoyo institucional, refiriéndose al Estado, representado en principio en la Alcaldía del municipio y en segunda instancia en el mismo ministerio. Se identificó que el 90\% de la muestra no tiene buenas relaciones con las administraciones municipales y no son tenidas en cuenta en los planes de desarrollo de los municipios. Las emisoras comunitarias no reciben un óptimo apoyo institucional, a menos que estas cedan ante las intenciones de la administración, de convertirse en un medio de propaganda del gobierno local de turno.

En segundo lugar, las secuelas del conflicto armado. Muchas emisoras siguen teniendo temor de las represalias que pueda haber en contra de ellas. En el caso particular de emisoras como Lobana Estéreo, del municipio San Martín de Loba; se prefiere no tocar temas que estén directa o indirectamente relacionados con el conflicto o sus secuelas. "si se habla de ello, es porque la comunidad o la autoridad misma lo hace, pero no porque como emisora propiciemos estos espacios".

En tercer lugar, los imaginarios en torno a la radio. El sondeo con la comunidad, evidenció que la mayoría de los y las radio oyentes, no tienen conocimiento sobre lo que es una radio comunitaria y el papel que esta debe ejercer en la comunidad, lo cual se constata al momento de llamar o interactuar con ellos. Por lo general se refieren a ellas como comerciales, parece un monologo aprendido e inculcado por las radios comerciales de la región. Se limita a la radio como el medio para escuchar música, mandar saludos, felicitaciones, servicios sociales y para pautas publicitarias, informar y entretener, nada más. Eso dificulta que la audiencia asimile otro tipo de contenidos basados en formatos diferentes a los acostumbrados, denotando una falta de tejido social, de empoderamiento de los discursos ciudadanos y democráticos, que permitan trascender la concepción del medio como instrumento para instalarlo en un lugar común donde todos se encuentren, participen y contribuyan al cambio 
social y el mejoramiento de los proyectos de vida. Si bien es claro que desde la comunicación no se solucionan los problemas estructurales de la sociedad, es igual de cierto que desde la comunicación, se remedia la manera social de asumir, pensar y gestionar las realidades.

\section{Municipios de baja productividad económica}

l Departamento de Bolívar tiene una gran riqueza natural, hídrica,
minera y agrícola; sin embargo, eso no ha sido suficiente para
que la situación económica de sus municipios sea buena, muchos,
especialmente en el sur del departamento, viven en extrema pobreza.

Bajo esta situación las emisoras deben buscar la manera de sostenerse y al ser las pautas publicitarias, su principal y prácticamente su única fuente de ingresos, la precariedad económica es heredada por las emisoras, pues si el pueblo no es económicamente productivo, no existen pautas que contribuyan. Hasta ahora ha sido posible para cada una de ellas mantenerse, pero el crecimiento del medio resulta muy limitado, "el paso de tortuga es el ritmo que nos preside", afirma uno de los directores. Ello, se aprecia y contrasta con el discurso del Estado relacionado con la interconectividad, las nuevas tecnologías y los esfuerzos de cobertura digital, pues mientras el MINTIC encamina todas sus estrategias para que los medios de comunicación del país y las comunidades en general incursionen en esta nueva cultura, aún existen proyectos locales que no alcanzan a superar los obstáculos financieros, logísticos, administrativos, sociales y conceptuales más elementales, que les ha impuesto la legislación.

La escasez de recursos lleva a que los grupos de realizadores de las emisoras sean limitados. En la mayoría, los participantes son locutores o locutoras que se integran de manera voluntaria, sin recibir retribuciones económicas; y si bien este es un proceso social sin ánimo de lucro, los voluntarios al no tener una fuente de ingresos oficial, buscan su sustento y el de su familia en otras actividades, lo que los lleva muchas veces a abandonar los procesos al interior de las emisoras o a no tener dedicación exclusiva para los planes de desarrollo o estratégicos de las radios en las que participan, repercutiendo en la constancia y continuidad de los procesos.

Si bien es cierto que algunas de las radios comunitarias del sur de Bolívar cuentan con la ventaja de pertenecer a una red como AREDMAG (Asociación de Radios Comunitarias del Magdalena Medio), reconocida por su valiosa 
labor comunitaria a través de las radios que la conforman, la construcción de agendas de gran impacto y la visibilización de sus realidades, la formación ciudadana de las comunidades, entre otros aspectos; las emisoras de norte y centro de Bolívar, no cuentan con esta misma oportunidad, por lo que el trabajo aislado hace más difícil y heroico el esfuerzo por superar el laberinto.

Desde el grupo de investigación Comunicación, Educación y Cultura de la Universidad de Cartagena y su línea Radio y Cambio Social, actualmente como producto de este esfuerzo se está adelantando se ha presentado al MINTIC y a la Universidad la propuesta de creación de REC BOL - una red de radios comunitarias cuya plataforma sea el conocimiento. La nueva red buscaría brindar oportunidades de formación tanto a emisores como a las audiencias en materia de radio, democracia, desarrollo, participación y fortalecimiento de la memoria colectiva. Construir una agenda común de temas relevantes para la región, promover los valores culturales de cada municipio asociado y diseñar y producir seriados radiales en torno a Bolívar. Esperamos desde la Universidad contribuir de manera concreta y práctica a que estos medios tan valiosos puedan fortalecerse y de esa manera incidir en el desarrollo del departamento.

\section{Discusión}

\footnotetext{
olombia fue pionera y precursora en la incursión de los medios masivos de comunicación en América Latina. El texto de Alfonso Gumucio Dragón, haciendo olas: historias de comunicación participativa para el cambio social, así lo evidencia; en un apartado de su texto que nos cuenta sobre cómo una radio comunitaria (Radio Sutatenza), de escaso presupuesto y producción artesanal logró convertirse en la primera emisora del país, con un importante alcance de transmisión. Pese a esto, hoy en día, la radio comunitaria ha venido decayendo en el cumplimiento de sus fines.
}

Lo cierto es que la decadencia no es del medio en general, sino de las funciones que la radio comunitaria debe ejercer, pues luego de hacer la batalla con emisoras de corte comercial y de interés público se encuentra enfrentada a sí misma, a su manera de hacer radio y su reto de educar e impartir cultura y democracia de una manera que resulte interesante para el público. Es justo en ese punto donde las radios deberían hacer uso de sus dos mayores tesoros: la audiencia y la programación, haciendo de ella lo que José Ignacio López llama Una declaración de amor: "La programación es la conversación planificada entre emisores y receptores... es la palabra conquistadora, la declaración de amor de ella, la radio, a él, el público. Candidatas hay muchas. Todas 
${ }^{6}$ López Vigil, José Ignacio. Manual urgente para radialistas apasio-

${ }^{7}$ Universidad Industrial de Santander. Informe final del estudio de características, alcances sociales e impacto de radiodifusión sonor en Colombia [Internet] Bucaramanga, Colombia, 2008dic. Disponible en URL: http://tinyurl. com/43d4lzj, 10 Sus traído de la página web de la asociación para e nidades (APC) URL de descarga: http://tinyurl. com $/ 3$ bkz $92 \mathrm{j}$ emisoras difunden música, noticias, todas hablan y esperan ansiosamente ser escuchadas. La diferencia radica precisamente en la manera de pronunciar esas palabras, esos sonidos sensuales que viajan a través de espacios inmensos para alcanzar multitudes... la programación es la coquetería de la radio, su estrategia particular de seducción ${ }^{6}$. Entonces iqué pasa con la radio comunitaria en Bolívar?

Teniendo en cuenta lo anterior, un estudio realizado hacia el año 2002 por el entonces llamado Ministerio de Comunicaciones, sobre el estado de la radio comunitaria en el país, arrojó que muchas de esas emisoras tienen graves problemas estructurales, frente a la paulatina desaparición de la radio comunitaria, estos resultados evidenciados hace once años, no están muy distantes de la realidad actual, lo que indica que nada ha ocurrido desde entonces. Las emisoras actuales presentan un estado precario, sin la infraestructura necesaria, con poca o nula participación por parte de la población, con un apoyo mínimo por parte del Estado, entonces es difícil no cuestionarse: ¿qué hace el Estado colombiano para mantener al aire a las emisoras comunitarias? Si bien es cierto que en 2001 el Ministerio de Comunicaciones propone una nueva reglamentación de las emisoras comunitarias (decreto 1981 de 2003), se les otorga una razón de ser que no dista mucho de la inicial, pero reglamentando su uso, abriendo las parrillas de transmisión a públicos infantiles y juveniles, promoviendo una responsabilidad social en prevención al abuso y consumo del alcohol y el tabaco, así como la música nacional y resaltando su calidad de pluralista y participativo, la anterior medida no se toma en cuenta por todas las emisoras, ya que la necesidad de autofinanciarse obliga a algunas a comportarse como emisoras comerciales que venden mucho más pautas publicitarias de las permitidas por el Estado.

Según el informe final del estudio de características, alcances sociales e impacto del servicio comunitario de radiodifusión sonora en Colombia; realizado por la Universidad Industrial de Santander ${ }^{7}$, existen 543 emisoras comunitarias en el país. Dichas emisoras poseen problemas específicos que pese a existir una reglamentación sobre su mantenimiento y financiación, amenaza con hacer que muchas desaparezcan. En ambos estudios se refleja una conclusión muy parecida, porque en nuestro proyecto vemos que existen problemas de financiación, estructura, participación e incluso de claridad en la razón de ser de la misma emisora, aun cuando ya esté establecida una reglamentación. 
El un documento del Consejo Nacional de Política Económica y Social (CONPES) República de Colombia, Departamento Nacional de Planeación que habla acerca de los lineamientos de política para el fortalecimiento del servicio comunitario de radiodifusión sonora muestra que en materia de participación ciudadana, existen debilidades en la convocatoria de los concesionarios a los diferentes sectores locales para que participen en las juntas de programación de la emisora, estas debilidades son muy semejantes a las encontradas en el presente proyecto ya que existe poca participación de la población en la elaboración de los manuales de estilo, en los eventos de rendición de cuentas sobre el quehacer de la emisora, en la conformación de colectivos ciudadanos de producción que reflejen los intereses y necesidades locales.

En este laberinto las radios comunitarias en Bolívar no se distancian de las demás radios comunitarias del país en cuanto a los problemas y limitaciones antes relacionados en los estudios previos. A pesar de ello, las radios luchan por sostenerse, por estar en la región. Todo indica que aún está lejano el día en que se cumplan los anhelos del gobierno en cuanto a indicadores de conectividad, educación con calidad, seguridad, salud, entre otros. Por ello, las radios comunitarias no han de condenarse a desaparecer sino por el contrario a crecer y convertirse en aliados estratégicos del Estado y de la ciudadanía. Bien lo ha dicho Mario Kaplún: " [La radio] Aspira, pues, a ser útil herramienta de trabajo en manos de aquellos que, sintiendo la comunicación como una vocación, no ven en la radio tan solo una profesión y un medio de vida, sino que la conciben como un instrumento de educación y cultura populares y como una promotora de auténtico desarrollo: que piensan que este, como todo medio de comunicación colectiva, tiene una función social que cumplir, un aporte que hacer frente a las urgentes necesidades de las masas populares de nuestra región" ${ }^{8}$.

\section{Conclusiones}

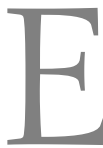

$\mathrm{n}$ la búsqueda de sí las emisoras comunitarias contribuyen al desarrollo social del Departamento, se encontró primeramente que no existe un concepto unificado del término entre las emisoras, lo que implica que cada aporte de desarrollo a sus municipios tiene las características según lo que desde las emisoras se está entendiendo como desarrollo, que ya han sido descritos en los resultados. Ahora, a la luz del concepto de desarrollo que tenido en cuenta para la presente investigación ("se trata de generar transformaciones sociales, hecho con capital humano y gestado desde la misma comunidad, es decir a través de la participación".) se puede decir que 
la mayoría de las emisoras estudiadas se encuentran lejanas a cumplir con ello e incluso con las exigencias generales de sus funciones hechas por la ley. Las emisoras no están generando aportes significativos a las comunidades, tal vez por sus dificultades estructurales y financieras, pero también por la falta de apoyo y trabajo mancomunado con las instituciones. Para el caso puntual de la emisora Carmen Estéreo, tendría que decirse que es la que ha dado un mayor cumplimiento a su esencia como emisora comunitaria, asociado, quizás de manera contradictoria al fuerte conflicto armado que vivió el municipio, pues aunque lo más razonable para ellos era cerrar, por las múltiples amenazas, la emisora se mantuvo, incluso informando al pueblo sobre lo sucedido y hoy día la emisora sigue incidiendo, ahora desde el postconflicto en la comunidad.

Al hablar de participación en las emisoras, fue posible encontrar que no existe una única manera de que las audiencias la ejerzan, pues el contacto con las emisoras va desde las llamadas telefónicas para solicitar canciones, hasta la participación de la comunidad haciendo programas y la inclusión de esta en los contenidos de los programas. Sin embargo, la participación es la posibilidad que tiene tanto emisora como comunidad de hacer de ese espacio una real herramienta de contribución al bienestar social, pero ello implica una participación más significativa. La del mayor contacto que tiene los escuchas con las emisoras estudiadas está concentrado en envío de saludos, felicitaciones y solicitud de canciones. La participación en cuanto a contenido, generación de nuevo programas o refuerzos de los mismos en muy escasa, la comunidad no se interesa y las emisoras se cansaron de insistir. En ese sentido la participación es solo una débil figura, que a pesar de sus múltiples maneras encontradas en la investigación, no está cumpliendo un papel significativo dentro de las comunidades.

Las comunidades no tienen muy en claro, por lo menos no su gran mayoría, que existe una clasificación de la radio, por tanto existen menos probabilidades de que estas conozcan la razón de ser de esa clasificación.. Esto de alguna manera influye en la poca conciencia e interés de las audiencias por las emisoras de carácter comunitario, que además de ser minorías se ven enfrentadas a la competencia abismal del entretenimiento y comercio.

Entonces, las emisoras han resuelto convertirse en unos híbridos con tal de ser escuchados y no perder el terreno ganado en sus comunidades, sino por el contrario ganar más audiencias. 
Al interior de las emisoras debe reforzase las capacitaciones que cada una necesita, pero también deben buscar estrategias para que de manera significativa puedan tener la atención y participación de sus comunidades y no asumir con resignación la combinación con formatos como el comercial como su única posibilidad de subsistir, porque ello estaría solo significando la permanencia del medio, pero no de su razón de ser. Lo cierto es que este no debería ser un compromiso independiente de las emisoras, se precisa necesaria la intervención del Min TIC, que cuenta con la estructura y conocimientos que necesita para hacer de estos medio el ideal, además de ser deber de Ministerio procurar y apoyar a las radio comunitarias para que cumplan con su objetivo, que entre otras cosas resulta supremamente significativo para el desarrollo integral del país.

\section{AGRADECIMIENTOS}

A la Universidad de Cartagena por su apoyo e impulso a la labor investigativa de los grupos de investigación y semilleros. Por la promoción y acompañamiento en este proceso.

Al Grupo de Investigación Comunicación, Educación y Cultura del Programa de Comunicación Social, por su respaldo y aportes en el desarrollo del mismo.

A los radialistas de las emisoras comunitarias que hicieron parte de la muestra y a las comunidades de cada municipio que nos acogieron durante el trabajo de campo.

Al Ministerio de Tecnologías de la Información y la Comunicación y a la Universidad Minuto de Dios por abrirnos las puertas y permitirnos socializar los resultados y generar sinergias.

\section{BIBLIOGRAFÍA}

Arnedo, Bertha. (2009) En la Onda de la Radio. Universidad de Cartagena, Cartagena de Indias.

Boisier Sergio, (2004) El desarrollo en su lugar (El territorio en la sociedad del conocimiento) Revista de Geografía Norte Grande.

Consejo Nacional de Política Económica y Social 3506 (2008). Lineamientos de política para el Fortalecimiento del Servicio Comunitario de Radiodifusión Sonora.

Palobra No. 14. Agosto de 2014 
Gumucio Dragón. Alfonso (2001). Haciendo olas: historias de comunicación participativa para el cambio social. New York, NY. The Rockefeller Foundation Haciendo referencia a: Colin Fraser -Sonia Restrepo Estrada.

Kaplún Mario. Producción de programas de radio, El guión-La realización. Ediciones CIESP

López Vigil, José Ignacio. Manual urgente para radialistas apasionados. Pág. 479

Ministerio de Comunicaciones (2004) Documento Políticas de Radiodifusión Colombiana, Bogotá, Colombia.

Najarro, L: (2007) Las potencialidades de la radio comunitaria, Cuba 2007 AL. 1990.

Pareja, Reynaldo, Historia de la radio en Colombia: 1929-1980, tomado de: http://www. banrepcultural.org/blaavirtual/ayudadetareas/periodismo/per75.htm

Resolución número 00415 de 13 abr. 2010, titulo v: radiodifusión sonora comunitaria. Bogotá, Colombia.

Universidad Industrial de Santander. Informe final del estudio de características, alcances sociales e impacto del servicio comunitario de radiodifusión sonora en Colombia [Internet] Bucaramanga, Colombia, 2008dic. Disponible en URL: http://tinyurl.com/43d4lzj. 